\title{
Childhood HIV-associated nephropathy: 36 years later
}

\author{
Patricio E. Ray ${ }^{1,2}$ (D) Jinliang $\mathrm{Li}^{2,3} \cdot$ Jharna R. Das ${ }^{2,3} \cdot$ Pingtao Tang ${ }^{2,3}$
}

Received: 28 April 2020 / Revised: 20 July 2020 / Accepted: 2 September 2020 / Published online: 12 October 2020

(C) The Author(s) 2020

\begin{abstract}
HIV-associated nephropathy (HIVAN) predominantly affects people of African ancestry living with HIV who do not receive appropriate antiretroviral therapy (ART). Childhood HIVAN is characterized by heavy proteinuria and decreased kidney function. Kidney histology shows mesangial expansion, classic or collapsing glomerulosclerosis, and microcystic renal tubular dilatation leading to kidney enlargement. The pathogenesis of HIVAN involves the kidney recruitment of inflammatory cells and the infection of kidney epithelial cells. In addition, both viral and genetic factors play key roles in this disease. Modern ART has improved the outcome and decreased the prevalence of childhood HIVAN. However, physicians have had modest success providing chronic ART to children and adolescents, and we continue to see children with HIVAN all over the world. This article discusses the progress made during the last decade in our understanding of the pathogenesis and treatment of childhood HIVAN, placing particular emphasis on the mechanisms that mediate the infection of kidney epithelial cells, and the roles of cytokines, the HIV-Tat gene, and the Apolipoprotein-1 (APOL1) gene risk variants in this disease. In view of the large number of children living with HIV at risk of developing HIVAN, better prevention and treatment programs are needed to eradicate this disease.
\end{abstract}

Keywords HIV nephropathy · Pediatric AIDS · Antiretroviral therapy · APOL-1 · Heparan sulfate proteoglycans $\cdot$ HIV-Tat · Infection of podocytes $\cdot$ Kidney epithelial cells

\section{Introduction}

HIV-associated nephropathy (HIVAN) was first reported in 1984 when a group of African-American adults infected with the human immunodeficiency virus-type 1 (HIV-1) presented with heavy proteinuria and rapid progression to kidney failure [1]. The identification of HIVAN in children provided key evidence to support the notion that HIV-1 per se was capable of inducing a new kidney disease, independently of other risk factors seen in adults [2]. The study of HIVAN attracted significant attention because it was a new kidney disease induced by a human retrovirus that was targeting people of African descent

Patricio E. Ray

Pray@virginia.edu

1 Department of Pediatrics, Child Health Research Center, University of Virginia School of Medicine, Room 2120, MR4 Building, 409

Lane Road, Charlottesville, VA 22908, USA

2 Center for Genetic Medicine Research, Children's National Hospital, Washington, DC 20010, USA

3 The George Washington University Health Center, Washington, DC 20010, USA
[1]. Childhood HIVAN is defined by the presence of proteinuria, often nephrotic syndrome, associated with mesangial hyperplasia and/or global-focal segmental glomerulosclerosis, and microcystic dilatation of renal tubules leading to kidney enlargement and failure [2-4] (Fig. 1). HIVAN bears a significant impact on the quality of life, treatment, and survival of HIVinfected children. Furthermore, it appears that once the clinical and renal histological features of HIVAN are well established, current treatments might not prevent its long-term progression to develop kidney failure. Therefore, it is necessary to improve our understanding of the pathogenesis and treatment of HIVAN in children. This article discusses the progress made during the last decade in our understanding of the pathogenesis and treatment of childhood HIVAN, focusing on the mechanisms that modulate the infection of kidney epithelial cells, and the role of cytokines, the HIV-Tat gene, and the Apolipoprotein-1 (APOL1) gene risk variants.

\section{What happens to children living with HIV today?}

Despite the promising progress made in the HIV response during the last years, children under 15 years of age account 
Fig. 1 Panels (a) and (b) show representative kidney sections from children with HIVAN. Panel (a) shows a kidney biopsy with collapsing glomerulopathy stained with period acid Schiff. Panel (b) shows a kidney biopsy with mesangial expansion and enlarged glomeruli stained with H\&E. Both panels show the tubular microcystic changes characteristic of childhood HIVAN (arrows). Original magnification $\times 200$
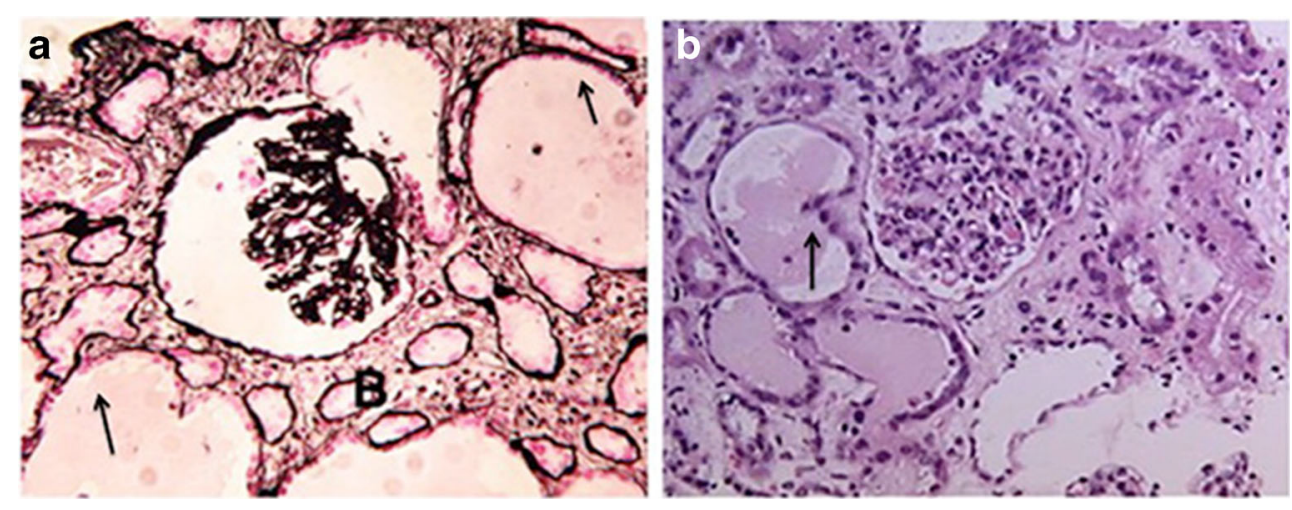

for about $5 \%$ of all people living with HIV, $9 \%$ of new HIV infections and 13\% of all AIDS-related deaths [5]. Those under 1 year of age are among those most vulnerable to HIV. If left untreated, they usually develop clinical symptoms in the first year of life, and by 1 year of age approximately one third of infected infants could die. Among the estimated 38 million people living with HIV in 2018, approximately 2.8 million were children under 19 years of age [6].

In countries where antiretroviral therapy (ART) has been successfully introduced, it has changed the face of HIV infection in a dramatic manner. Since 2010, new HIV infections among children have declined by $41 \%$, but only half (54\%) of all children living with HIV are getting treatment, and 100,000 children died of AIDS-related illnesses in 2018 (UNAIDS, Global AIDS update, 2019). The majority of these children acquired HIV-1 from their mothers during pregnancy, birth, or breast feeding. In addition, as of 2018, roughly 14.9 million children under the age of 18 had lost one or both parents to AIDS, and many have been affected by poverty, homelessness, and malnutrition. Modern ART, in combination with the avoidance of breastfeeding and good access to HIV and pregnancy care services, has reduced the risk of mother-to-child HIV transmission to 1-2\% [7]. HIV-infected infants now survive to adolescence and adulthood, but they need to receive daily effective ART treatment to remain in good health. However, as discussed above, these therapies are still not widely accessible in most resource-limited countries, where the burden of HIV-infection is very high.

African Americans represent approximately 65\% of all children with HIV-1 infection or AIDS in the USA. In addition, over $80 \%$ of the estimated number of children under 15 years of age living with HIV reside in sub-Saharan Africa [5]. Since HIVAN is seen almost exclusively in Black children, the majority of children living with HIV are at higher risk of developing HIVAN if they are not treated appropriately with ART. However, providing chronic ART and good medical care to children living with HIV remains a big challenge all over the world. Unfortunately, the true prevalence of childhood HIVAN is unknown since in many pediatric centers, kidney biopsies have not been performed regularly. Studies done in the early years of the AIDS epidemic reported a prevalence of childhood HIVAN of approximately $10-15 \%$ in populations with a majority of Black children [2,3]. Subsequently with the development of highly effective ART, the prevalence of HIVAN decreased significantly, but we continue to see children who develop HIVAN because they do not receive appropriate ART. In addition, persistent proteinuria, which could be the first clinical sign of HIVAN, is common in children living with HIV on ART, and the prevalence of proteinuria in these patients ranges from 5 to $10 \%$ [4, 8]. Table 1 describes epidemiological, clinical, diagnostic, histological, and laboratory features typical of children and adolescents with HIVAN.

\section{Pathogenesis of childhood HIVAN}

Lessons from HIV-transgenic ( $\mathrm{Tg}$ ) mice Our understanding of the pathogenesis of HIVAN has evolved throughout the years in correlation with the rapid progression made in the field of HIV. A major early breakthrough was made at the National Institutes of Health in 1991, with the generation of HIV-1 transgenic (HIV-Tg ${ }_{26}$ ) mice that developed a HIVAN-like disease [9]. This mouse model was developed with a replication defective HIV construct driven by the HIV-LTR but lacking a 3-kb sequence overlapping the gag and pol HIV genes that are essential for viral replication [9]. Despite the limited activity of the HIV-tat gene in rodents, which is necessary for HIV transcription, these mice express HIV-1 mRNA in a wide range of tissues, including kidney glomerular and tubular epithelial cells [10]. HIV-Tg rats generated with the same HIV- $\Delta$ gag/pol transgene [11] show a similar kidney localization of HIV-genes, and develop the typical histological features of childhood HIVAN, including mesangial hyperplasia, visceral epithelial cell enlargement, glomerular sclerosis, tubular cell proliferation, and tubular microcystic changes. One distinguishing feature of the HIV-Tg rat model, however, is that the HIV-transgene is more widely expressed, and the HIV protein gp120 is detected in the circulation and mononuclear cells [11]. These findings suggest that HIV-tat may be more active in rats. Overall, both HIV-Tg mouse and rat models 
Table 1 Typical features of HIVAN in children from the Washington, D.C. area

\section{Epidemiology}

Almost exclusively seen in Black children and adolescents

Majority acquired HIV-1 through vertical transmission ( 97\%)

Clinical onset: any time after 1 year of age, more frequent during late childhood and adolescence

Both sexes

In children from other ethnic groups, suspect other kidney diseases

In children with consistently suppressed viral load, suspect other kidney diseases

Early clinical and laboratory diagnosis

Requires a high index of suspicious

Mild or moderate persistent proteinuria

A dipstick proteinuria 1+, in the absence of acute infection episodes, requires a quantitative assessment of proteinuria and clinical follow-up

Normal BUN and SCr levels

Normal blood pressure

Abnormal urinary sediment, casts, shedding of renal epithelial cells

If significant hematuria, elevated $\mathrm{SCr}$, or hypertension are present initially, suspect other kidney diseases

Late clinical and laboratory diagnosis

Gross proteinuria, nephrotic syndrome

Abnormal urinary sediment, cast, shedding of renal epithelial cells and microcysts

High BUN and SCr levels

Hypertension

Hyperlipidemia

Fluids - electrolyte and salt wasting disorders

Sonogram: enlarged echogenic kidneys

Renal histology

A kidney biopsy is needed to confirm the diagnosis of HIVAN. "It is not always HIVAN"

Glomerular enlargement, mesangial hyperplasia

Classic or collapsing focal glomerulosclerosis

Microcystic tubular dilatation

Tubulointersitial injury and recruitment of inflammatory cells

Course

Usually associated with other AIDS symptoms

Depends on adherence and response to ART

Mild, moderate, or gross persistent proteinuria

Slow progression to kidney failure depends on the stage of diagnosis and ART response

Early diagnosis and treatment may reverse the progression of HIVAN

A late diagnosis or treatment is unlikely to reverse the progression

Death from other AIDS-related complications

HIVAN HIV-associated nephropathy, BUN blood urea nitrogen, $S C r$ serum creatinine, $A R T$ antiretroviral therapies

demonstrate that the expression of HIV genes in kidney epithelial cells play a critical role in the pathogenesis of HIVAN. In addition, many other HIV-Tg mouse models, which were described in detail in a previous review [12], highlighted the role of two accessory HIV genes, nef (Negative regulatory factor) and $v p r$ (viral protein R), as key determinants in the pathogenesis of HIVAN in these mice. It is worth mentioning, however, that not all HIV-Tg mice or rats that express HIV genes in the kidney develop kidney disease. Furthermore, when F1 hybrids of $\mathrm{HIV}-\mathrm{Tg}_{26} \mathrm{FVB} / \mathrm{N}$ were crossbred with five other inbred mouse strains, there were striking variations in the kidney phenotype of HIV- $\mathrm{Tg}_{26}$ mice [13]. These studies demonstrate that a strong genetic influence modulates the outcome of HIVAN in mice, and suggest that other still unknown genetic and/or environmental factors may be needed to develop the complete HIVAN phenotype in mice.

Infection of kidney epithelial cells Since kidney epithelial cells do not express the CD4 molecule, which is the major HIV-1 receptor, a major controversy in the pathogenesis of HIVAN is whether these cells can become productively infected. HIV1 induces a productive infection of $\mathrm{T}$ cells mainly by a process that involves the fusion of its envelope protein (gp120-gp41) to the plasma membrane [14], which is triggered by the interaction of gp120 with the CD4 molecule in collaboration with the HIV-1 co-receptors CXCR4 or CCR5. In 1998, kidney epithelial cells cultured from the urine of children with HIVAN were used for the first time to demonstrate that HIV-1 isolates derived from children with HIVAN can induce a low-level productive infection in the absence of CD4 [15]. These tubular epithelial cells produced low levels of p24 antigen when compared with HIV-infected macrophages, but were able to transfer viruses and infected co-cultured HIVnegative mononuclear cells even after 20 days in culture [15]. In addition, the present study showed that cell-to-cell contacts between HIV+ mononuclear cells and kidney epithelial cells is the most efficient mechanism to infect the latter cells [15] (Fig. 2). Subsequent studies confirmed the presence of viral transcripts in podocytes and kidney tubular epithelial cells in kidney sections derived from patients with HIVAN [16]. Nonetheless, other studies done in podocytes and kidney tubular epithelial cells cultured from HIV-negative people concluded that these cells were not productively infected $[17,18]$. In contrast, another study confirmed that interactions between infected $\mathrm{T}$ cells and kidney tubular epithelial cells create virological synapses that allow viral uptake and gene expression in kidney epithelial cells [19].

In any case, many studies support the notion that HIV-1 can enter CD4 negative kidney epithelial cells via endocytosis. Our previous infection studies done in primary kidney tubular epithelial cells cultured from children with HIVAN showed HIV-1 particles in intracellular compartments [15] (Fig. 2). In addition, although the endocytic uptake of HIV particles usually leads to a non-productive infection when viruses are degraded in the lysosomes, it is possible that some viruses that are internalized via endocytosis prior to membrane fusion can complete its fusion process within endosomes or escape into the cytosol [20]. Dynamin, a 100$\mathrm{kDa}$ GTP-ase that mediates the release of endocytic vesicles from the plasma membrane, can facilitate the escape of HIV-1 from endosomes [20]. In contrast, dynasore, a small molecule inhibitor of the dynamin GPT-ase activity, prevents the scission of endocytic vesicles from the inner leaflet of the plasma 
Fig. 2 Panels (a) and (b) show a mononuclear cell on top of renal tubular epithelial cells (RTEC) cultured from a child with HIVAN. The arrowhead in panel (a) points to a tight junction between RTEc. The arrow points to HIV viral particles inside RTEc. Panel (b) shows a higher magnification of the viral particles inside RTEc, as well as viral particles in the space between mononuclear and RTEc (arrow). Original magnification $\times 10,000$ (a) and $\times 50,000$ (b)
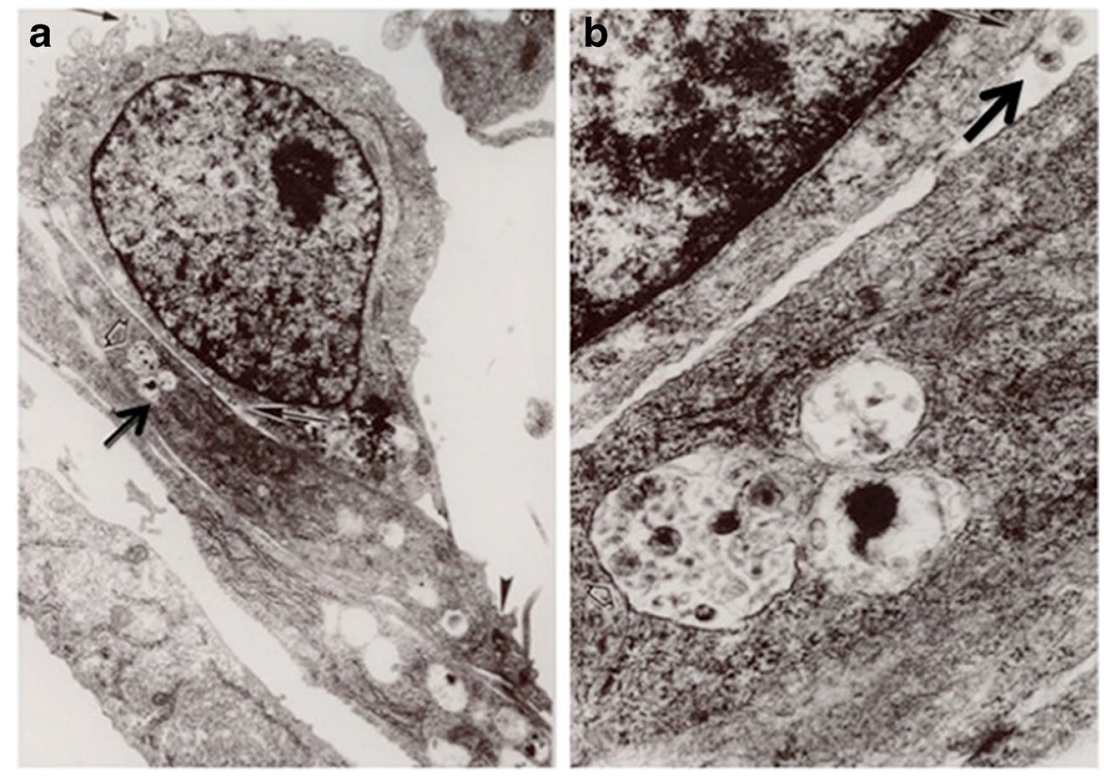

membrane and inhibits clathrin-mediated endocytosis, as well as the fusion of HIV-1 to endosomes [20]. Taken together, these findings imply that cells could potentially become productively infected, although at low levels, via endocytosis through an envelope glycoprotein-dynamin-dependent fusion within intracellular compartments [20]. HIV-1 infection via endosomes has been reported in macrophages, lymphocytic cells, and HeLa cells [21], and two studies showed that HIV-1 enters cultured human podocytes via dynasoremediated endocytosis [18, 22]. In summary, HIV is efficiently taken up by clathrin-coated vesicles [23] and dynamins can facilitate the release of these vesicles from the plasma membrane and endosomes.

Role of trans-membrane TNF- $a$ enhancing the infection of cultured kidney epithelial cells In 2017, we described a new role for transmembrane TNF- $\alpha$ (tm-TNF- $\alpha$ ), facilitating the infection of CD4-negative podocytes and tubular epithelial cells cultured from children with HIV-associated kidney diseases [22]. More specifically, we found that tm-TNF- $\alpha$ expressed in podocyes cultured from children with HIVAN, increases the viral entry process via a dynamin-mediated mechanism that is blocked by dynasore, and enhances the replication of HIV-1 in these cells via an NF-kB-mediated mechanism [22]. Heparan sulfate proteoglycans (HSPG) also play a critical role in this process, enhancing the attachment and entry of the HIV-1 envelope protein [22]. After viral entry, the precise mechanisms through which tm-TNF- $\alpha$ facilitates the release of HIV-1 into the cytoplasm and its integration in the nuclei of podocytes remain undefined. In this regard, it is worth mentioning that tm-TNF- $\alpha$ is the precursor of soluble TNF- $\alpha$, and can act both as a ligand or as a receptor [24]. Therefore, tm-TNF- $\alpha$ can induce cell-to-cell contactdependent signaling and also raise the concentration of soluble TNF- $\alpha$ in the proximity of TNF receptors (TNFR) [24]. These events enhance the expression of cell adhesion and signaling molecules involved in viral entry and replication. Furthermore, tm-TNF- $\alpha$ activates the non-canonical NF$\mathrm{kB}$ pathway acting through TNFR2, which has higher affinity for tm-TNF- $\alpha$ than soluble TNF- $\alpha$ [24, 25]. Finally, through all these mechanisms, tm-TNF- $\alpha$ may facilitate the formation of viral synapses between mononuclear and kidney epithelial cells $[15,19]$ (Fig. 3). Taken together, these findings suggest that kidney epithelial cells may be "primed" by tm-TNF- $\alpha$ to become latently or productively infected, albeit at low levels, when they interact with HIV-infected mononuclear cells. Furthermore, studies in homozygous HIV-Tg ${ }_{26}$ mice showed that high circulating levels of TNF- $\alpha$ precipitate the death of these mice, and this process can be ameliorated with antiTNF- $\alpha$ antibodies [26]. In addition, TNF- $\alpha$ appears to worsen the progression of HIVAN in heterozygous $\mathrm{Tg}_{26}$ mice, probably by enhancing the expression of HIV-genes and inducing podocyte injury [27]. In summary, since high levels of TNF- $\alpha$ are detected in the plasma of HIV+ children [28], these studies suggest that TNF- $\alpha$ may play an important role in the pathogenesis of childhood HIVAN.

Novel roles of HIV-tat in childhood HIVAN The HIV-Tat protein is a powerful transcriptional factor encoded by two exons. The first exon encodes the activation domain, which interacts with cyclin T1, and the basic domain (amino acids 49-57), which is required for the nuclear localization of Tat [29]. The second exon encodes the RGD motif (C-terminal amino acids 73-86), which enhances the angiogenic activity of Tat acting through integrin receptors [30]. Tat plays an essential role in HIV replication by recruiting a cellular human protein called cyclin $\mathrm{T} 1$, which efficiently increases viral transcription, and also induces the activation of NFKB and the HIV-LTR [31]. 

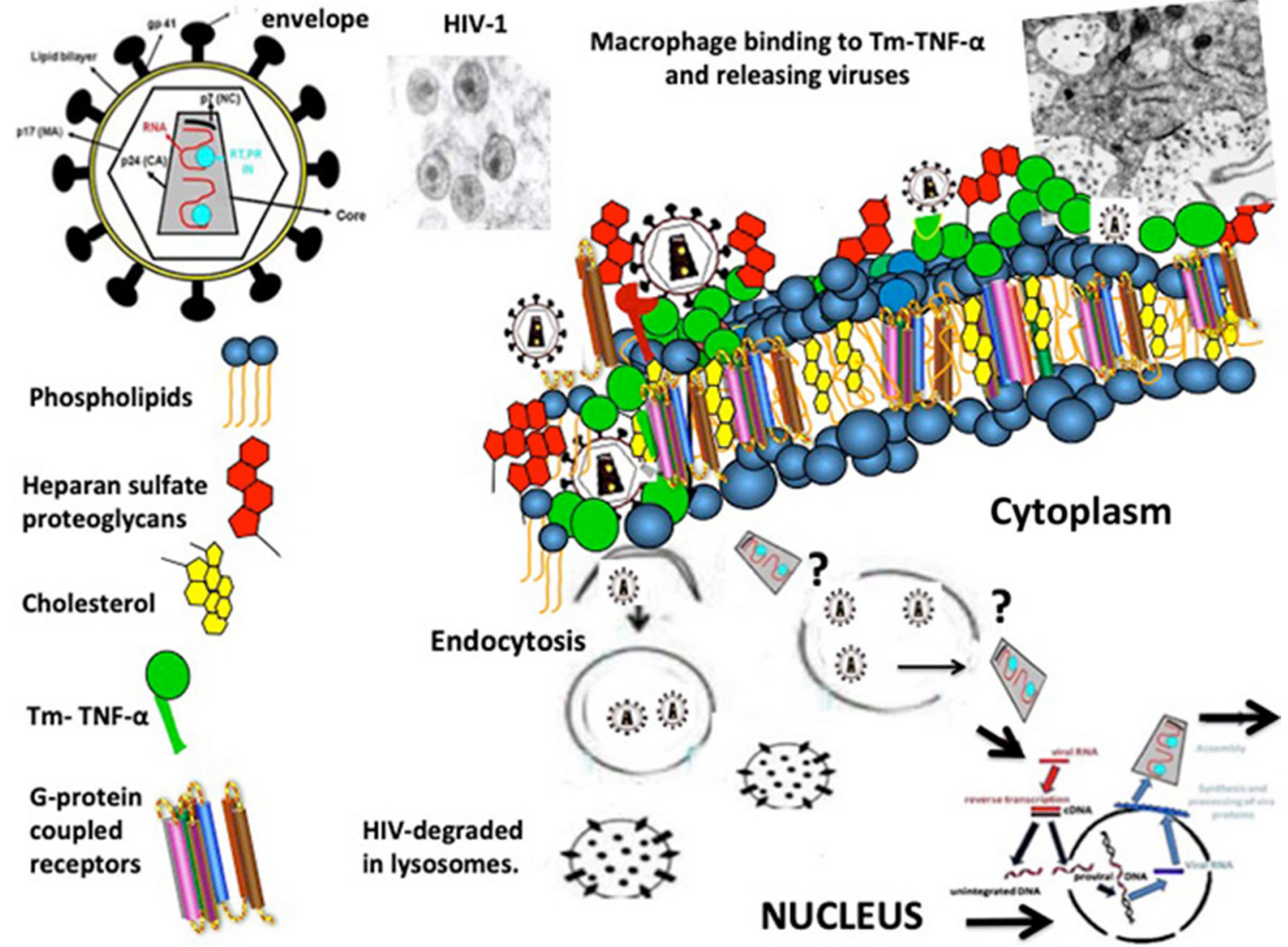

Fig. 3 Proposed mechanisms for explaining the infection of kidney epithelial cells cultured from children with HIVAN. TransmembraneTNF- $\alpha$ (Tm-TNF- $\alpha)$ expressed on the surface of kidney epithelial and mononuclear cells facilitates the binding of HIV-infected mononuclear cells to kidney epithelial cells. Viruses are released into a "virological synapse" created between these cells (Fig. 2). HIV is internalized via an envelope-clathrin-mediated endocytosis mechanism prior to membrane fusion. Heparan sulfate proteoglycans facilitate the binding and entry of

Cloning and characterization of the murine CycT1 protein revealed that mouse cyclin 1 lacks a critical cysteine residue that is needed to form a complex with HIV-1 Tat and increase HIV-1 transcription [32]. Because both the infection and HIVreplication processes are bypassed in HIV-Tg mice, and murine cyclin 1 has weak interactions with Tat, transgenic mice are not the ideal experimental model to elucidate the role of HIV-Tat in the pathogenesis of HIVAN.

One characteristic feature of HIVAN in children is the upregulation of renal heparan sulfate proteoglycans (HSPG) (Fig. 4). HIV-Tat and other heparin binding growth factors released by infected cells can interact with negatively charged HSPG expressed in glomerular, tubular epithelial, and kidney interstitial cells [33]. In this manner, extracellular Tat can act as a cytokine [34], entering cells via endocytosis mediated by HSPG, and increasing the replication of HIV-1 via TNF- $\alpha$ and $\mathrm{NF}-\mathrm{kB}$ activation [35]. In addition, in recent years we found that Tat is preferentially recruited to lipid rafts (LR) in podocytes cultured from children with HIVAN [36]. LRs are
HIV-1 via endocytosis. Once inside endosome-like compartments, viral particles can be degraded in endolysosomal compartments (non-productive infection). A small number of virus particles may undergo fusion in endosome-like compartments or escape into the cytosol through other mechanisms that are not clearly understood at the present time (?). Viral particles released into the cytoplasm undergo reverse transcription and integration into the nucleus. In turn, after undergoing several assembling steps, new infectious viral particles can be released

specialized membrane domains enriched in certain lipids, cholesterol, and proteins that serve as docking sites for signaling proteins, including G protein-coupled receptors [37]. Actin binding proteins bind to polyphosphoinositides located in LRs, and these proteins link the actin cytoskeleton with signaling molecules that are enriched in the LRs [38]. In fact, activation of G protein-coupled receptors by HIV-Tat in endothelial cells activates Rho-kinase and the myosin binding subunit of the myosin light chain (MLC) [39]. Rho-A regulates the dynamic organization of contractile actin-myosin filaments and stress fiber formation through activation of Rho-kinase and MLC [40]. These molecules play an important role maintaining the cytoskeletal structure of podocytes as well as the permeability of the glomerular basement membrane (Fig. 5). Analogous changes in Rho-A activation were induced in the kidney of HIV-Tg ${ }_{26}$ mice infected with adenoviral Tat vectors, and they precipitated the development of HIVAN [36]. In a similar manner, previous studies showed that activation of the Rho-A pathway specifically in podocytes 


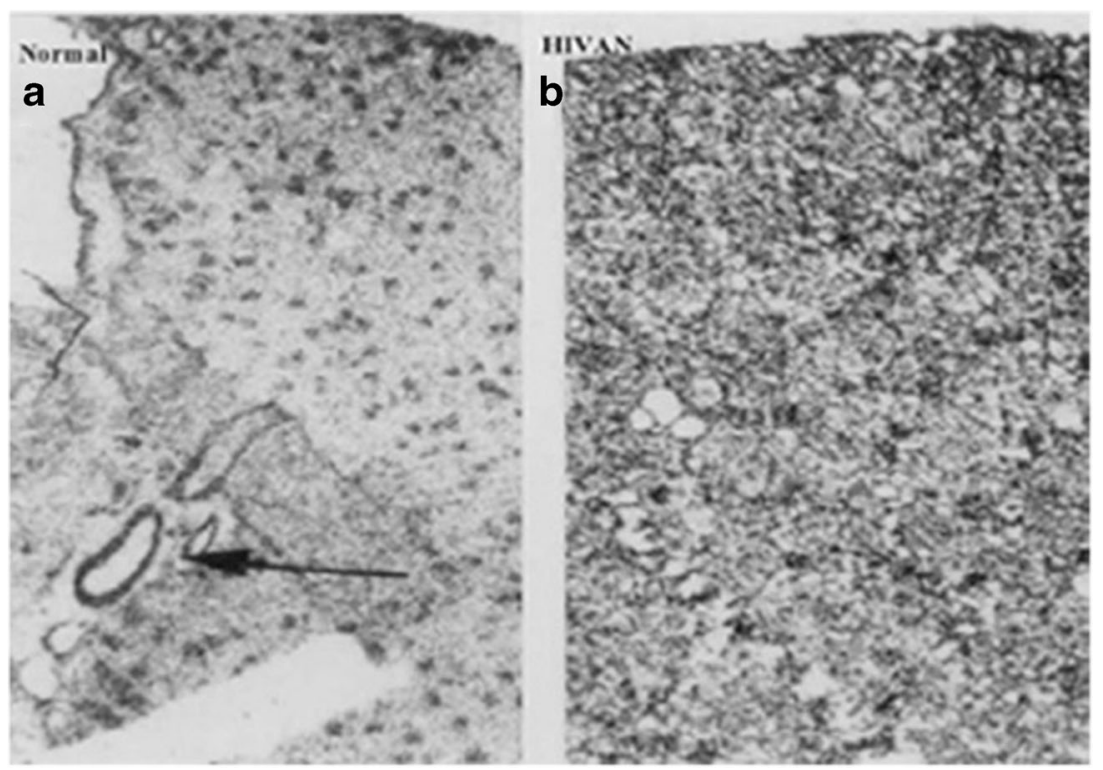

Fig. 4 Total binding of ${ }^{125}$ I-Fibroblast Growth Factor- 2 to heparan sulfated proteoglycans (HSPG) located in glomeruli, vessels, and the kidney interstitium of children with and without HIVAN. Panel (a) shows a representative kidney section from a control child (normal). The arrow in panel (a) points to ${ }^{125}$ I-FGF binding to kidney vessels. Panel (b) shows increased binding of ${ }^{125}$ I-FGF to HSPG in the kidney cortical interstitium in a child with HIVAN. Original magnification $\times 60$. (Figure is reproduced with permission of Springer from Ray PE, Liu Xu, Rakusan T, Liu Xue-Hui. "A 20-year history of childhood HIV-associated nephropathy" Pediatric Nephrology 19: 1075-1092, page 1083; License Number 3984431229899)
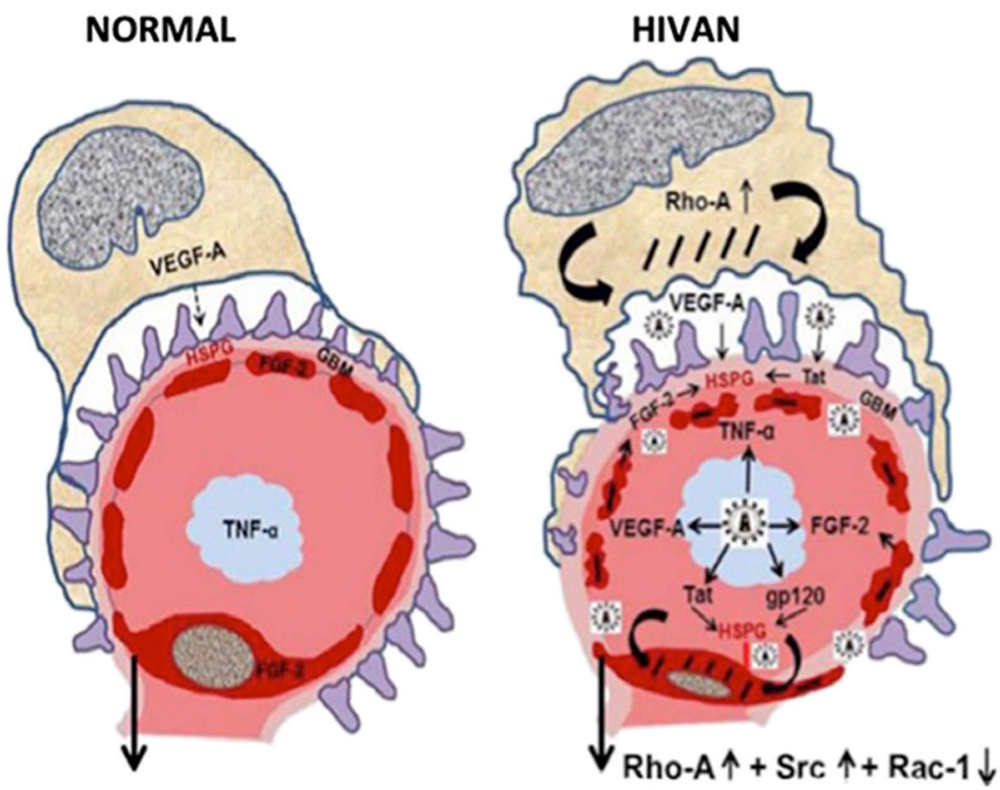

Normal

Increased glomerular permeability

Fig. 5 HIV-Tat, fibroblast growth factor-2 (FGF-2), and vascular endothelial growth factor (VEGF-A) increase the permeability of the glomerular filtration barrier. Under normal conditions, VEGF-A released from podocytes is needed to maintain the normal structure and survival of endothelial cells. FGF-2 is not released from healthy endothelial cells, and very low levels of TNF- $\alpha$ are released from mononuclear cells. In contrast, during the early stages of HIVAN, HIV-Tat and other heparin binding cytokines or viral proteins released by HIV-infected mononuclear cells, injured endothelial cells, or podocytes affect the phosphorylation and activity of Rho-A, Src, and Rac-1 in podocytes and glomerular endothelial cells. These changes alter the cytoskeleton structure of podocytes and glomerular endothelial cells and increase the permeability of the glomerular filtration barrier causing proteinuria 
causes chronic kidney failure in transgenic mice [41]. Furthermore, the Tat basic domain, which contains a cluster of basic residues (RKKRRQRRR) that are known to carry proteins and DNA molecules across the cell membranes, appears to be essential for the recruitment of Tat to LRs [36], and to modulate the activity of extracellular Tat in human podocytes $[29,36]$. Three arginine residues in the basic domain are essential for the stable association of Tat with LRs and Tat's signaling interactions with heparin binding growth factors in podocytes cultured from children with HIVAN [36].

Finally, matrix metalloproteinases (MMP) can also modulate the activity of Tat. Children with HIVAN excrete high levels of MMP in the urine, in correlation with the progression of their kidney disease [42]. MMP-9 belongs to a family of zinc binding endopeptidases that degrade extracellular matrix proteins, including HSPG and collagen [43], and facilitates the release of Tat and Fibroblast Growth Factor-2 (FGF-2) bound to HSPG [44]. We found that MMP-9 was localized in LRs in human podocytes, and that the basic domain of Tat increased the expression of MMP-9 in LRs [36]. Furthermore, the substitution of six arginines in the Tat basic binding domain for alanines prevented the association of Tat with LRs, impaired its ability to enhance FGF-2 signaling or MMP-9 expression in cultured podocytes, and failed to induce severe kidney disease in HIV-Tg 26 mice [36]. Taken together, these data suggest that the Tat basic binding domain could become a new target to develop therapies against childhood HIVAN.

Renal proliferative lesions and childhood HIVAN As discussed before, HIV- $\mathrm{Tg}_{26}$ mice provided an important clue to understand the pathogenesis of the kidney epithelial proliferative changes characteristics of HIVAN. Briefly, the natural history of the kidney disease in HIV- $\mathrm{Tg}_{26}$ mice can be divided in two different stages [33]. The first stage is associated with an upregulated expression of HIV genes in kidney epithelial cells and the onset of proteinuria. No direct kidney epithelial proliferative changes are noted at this stage [33]. In patients with a high viral load, the first stage involves the kidney recruitment of cytokines, viral proteins, and inflammatory cells that injure podocytes and tubular epithelial cells (Fig. 6). The second stage of HIVAN in HIV-Tg 26 mice, is characterized by glomerular and tubular epithelial proliferative changes, and is associated with lower levels of HIV gene expression and the accumulation of heparin binding growth factors bound to renal HSPG (Fig. 6). It is unclear whether the proliferating cells seen in Bowman's space are de-differentiated podocytes, parietal epithelial cells, or progenitor epithelial cells. The tubular microcystic changes are composed of flattened epithelial cells that express very low levels of HIV genes [33]. These more primitive kidney epithelial cell types appear to have a limited transcriptional activity to support HIV gene expression. Podocytes or tubular epithelial cells cultured from the urine of children with HIVAN do not proliferate when exposed to
HIV [15]. Taken together, these data do not support the notion that HIV-1 genes induce direct proliferative changes in kidney epithelial cells cultured from children. In contrast, previous studies done in cultured murine epithelial cells immortalized with the SV-40 large T antigen showed that HIV-Nef increases the proliferation of these cells [45]. However, these findings were not reproduced in primary human kidney epithelial cells.

As discussed above, the kidney accumulation of heparin binding growth factors appears to play a critical role inducing the de-differentiation and proliferation of podocytes and tubular epithelial cells [33, 46, 47]. Podocytes are terminally differentiated cells, and when they are forced to proliferate, they can detach, die, or undergo apoptosis [48, 49]. These cells, however, can be replaced by parietal epithelial cells or renal progenitor cells $[50,51]$, which are sensitive to FGF-2 and other cytokines [52]. In addition, we found that FGF-2 and VEGF-A potentiate the ability of HIV-Tat to induce cytoskeletal changes and increase the permeability of cultured podocytes and endothelial cells [53]. Finally, the urinary levels of FGF-2 and VEGF-A are elevated in children with HIVAN, and these cytokines appear to be good candidate biomarkers to follow the outcome of childhood HIVAN [42, 53]. Current studies are underway to determine the sensitivity and specificity of these heparin binding growth factors to follow the outcome of children with HIVAN. Children may be more sensitive to the kidney accumulation of FGF-2 because their kidneys are growing, and they have high expression levels of HSPG, MMPs, FGF receptors, and higher plasma and tissue levels of FGF-2 compared with adults [54].

\section{Apolipoprotein-1 and host genetic susceptibility to develop} HIVAN People of African descent are at markedly increased risk for developing HIVAN. The discovery in 2010 that two common genetic variants of the APOL1 gene, named G1 and $\mathrm{G} 2$, located in a region of chromosome 22q12 were strongly associated with the risk of developing HIVAN, constituted a major breakthrough in understanding why mainly people of African descent develop HIVAN $[55,56]$. In sum, two haplotypes harboring three coding sequence mutations of APOL1 were identified as risk variants. The first one, termed G1, is a two-non-synonymous-SNP haplotype (rs73885319 (A $\rightarrow$ G; $\mathrm{S} 342 \mathrm{G})$ and $\mathrm{rs} 60910145(\mathrm{G} \rightarrow \mathrm{T}$; I384M)). The second one, termed G2, is a two-codon-deletion haplotype (rs71785313 (6 bp in frame deletion; DN388Y389)). The APOL1 risk variants increase the lifetime risk for people with untreated HIV+ to develop HIVAN by $\sim 50 \%$ [57]. It should be noted, however, that a significant number of HIV+ children of African descent develop HIVAN independently of the APOL1 risk variants $[58,59]$. In fact, previous studies done in the USA suggest that the APOL1 risk variants may play a more relevant role in adults when compared with young children [59, 60]. Thus, it is possible that other unknown genetic factors may 


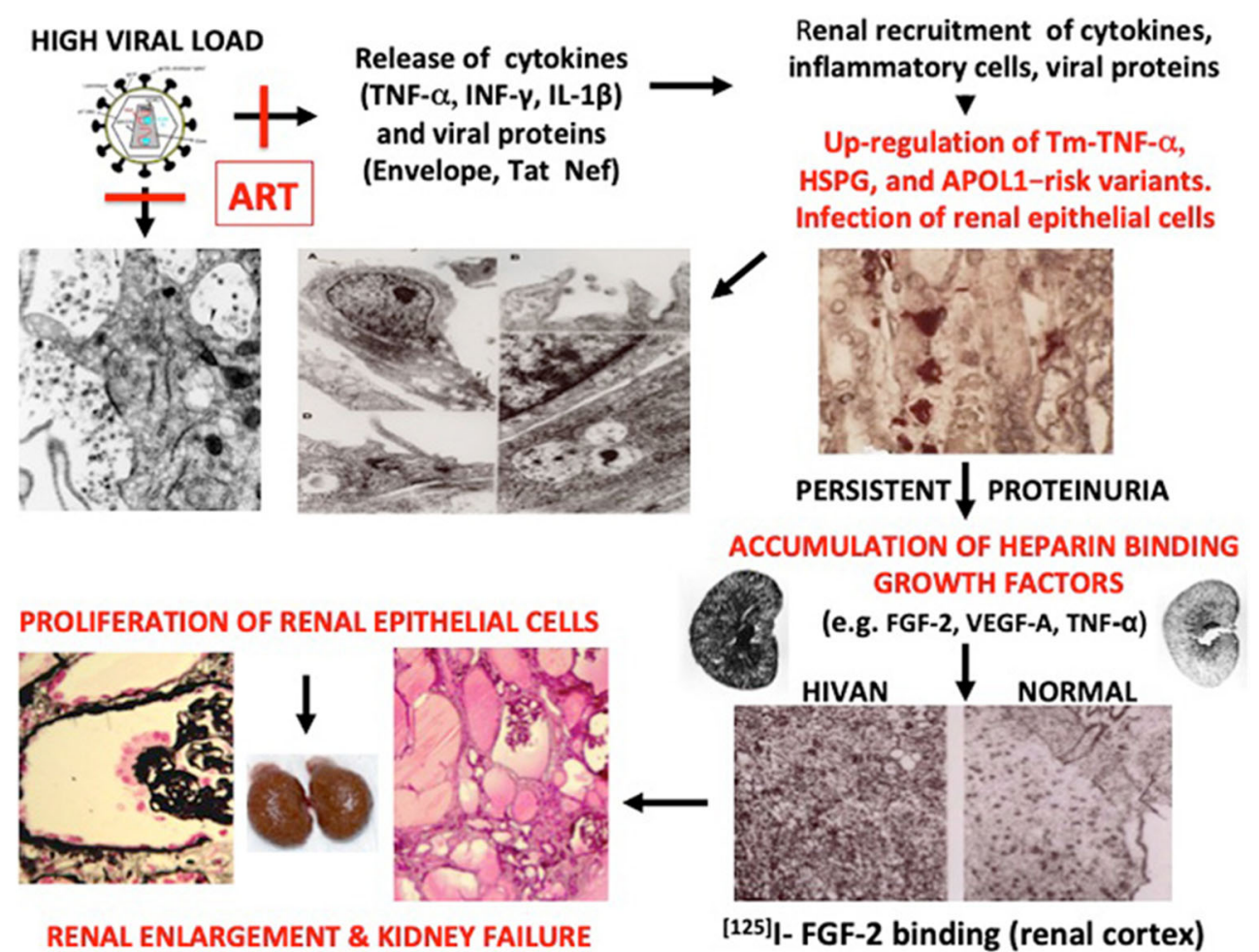

Fig. 6 Proposed mechanisms for explaining the pathogenesis of childhood HIVAN. A high viral load increases the release of cytokines and viral proteins in the circulation. Cytokines, viral proteins, and inflammatory cells are recruited in the kidney, increasing the expression of Tm-TNF- $\alpha$, heparan sulfate proteoglycans, and APOL1 in kidney epithelial, endothelial, and tubulointerstitial cells. All these changes induce glomerular and tubulointerstitial injury, increasing the recruitment of inflammatory cells, and facilitating the infection and

play an additional role precipitating HIVAN in Black children. However, a recent study in African children living with HIV found a 22-fold increase odds of albuminuria ( $\geq 30 \mathrm{mg} / \mathrm{g}$ ) in those carrying the high-risk APOL1 genotypes when compared with children carrying the low-risk genotype [61].

The effects of the APOL1 risk alleles in kidney epithelial cells have been discussed in depth in previous studies [62-64]. Briefly, APOL1 has been localized in several tissues, including podocytes, tubular epithelial cells, endothelial, and vascular smooth muscle cells [65]. Unfortunately, despite extensive research efforts, we still do not have a good understanding of how the APOL1 risk variants predispose to the development of HIVAN. However, several studies done in cultured kidney cells [62-64], transgenic mice [66, 67], and transgenic flies $[68,69]$ have provided relevant information. In general, all these studies show that the APOL1 G1 or G2 risk variants, when overexpressed, are more toxic than the wild-type APOL1. In addition, the endogenous expression of APOL1 is induced by TNF- $\alpha$ and IFN- $\gamma[62,70]$, two cytokines released by HIV-infected cells. These findings are consistent with the hypothesis that HIV acts as a second hit, enhancing the toxicity of the APOL1 risk variants in podocytes, rather that inducing direct proliferative changes in these cells. In

injury of more kidney epithelial cells causing persistent proteinuria. The accumulation of heparin binding growth factors and viral proteins increase the proliferation of podocytes and tubular epithelial cells leading to kidney enlargement and kidney failure. Antiretroviral therapy (ATR) blocks the early stages and development of HIVAN, but may not affect the secondary proliferative changes once the kidney damage is established

turn, injured podocytes may be replaced by proliferating parietal epithelial cells or progenitor cells, and this process is more likely to be driven by cytokines and heparin binding growth factors accumulated in the kidney (Fig. 6).

Treatment of HIVAN ART has substantially changed the face of children living with HIV-associated kidney diseases. In a large multi-center trial evaluating long-term outcomes in children living with HIV, the death rate attributable to CKD was $\sim 2 \%$ [71]. However, children living with HIV need to be enrolled in effective chronic treatment programs to stay healthy, and providing continuous acute and chronic care to these patients is a major challenge today. Obstacles to treating all pediatric patients include the lack of screening or simple diagnostic tests, insufficient understanding of the beneficial effects of ART by the parents, and the cost of pediatric ART formulations. In resource-limited countries, even children on ART show poor clinical outcomes [72]. In these cases, additional efforts are needed to make antiretroviral drugs available to more children, and to develop simple treatment strategies to assure the long-term adherence to these treatments. Most countries have moved or are moving to provide lifelong ART regardless of CD4 cell count to all pregnant and 
Table 2 General guidelines for the treatment of children and adolescents with HIVAN

Treatment goal: achieve virological suppression causing the least possible systemic and renal toxicity

Treatment team: always include nephrologists and HIV-infectious diseases experts

Preferred ART regimen: two nucleoside reverse transcriptase inhibitors (NRTIs) plus one drug from one of the following classes: integrase inhibitors (INSTI), non-nucleoside reverse transcriptase inhibitors (NNRTI), or a boosted protease inhibitor (PI). The regimen should be simple to assure adherence

Choice of regimen: should take into consideration the patient's age, body weight, sexual maturity, results of drug-resistance testing, dosing frequency, food or fluid requirements, pill size, availability of palatable pediatric formulations, drug interactions, and preference of the patients and caregivers

Doses and regimen selection: recommend following the guidelines of the "Panel on ART and medical management of children and adolescents living with HIV, which are updated frequently when the FDA approves new drugs and regimens: http://aidsinfo.nih.gov/contentfiles/lvguidelines/pediatricguidelines

Co-infections: Children and adolescents with tuberculosis or hepatitis should receive specific ART regimens, as discussed in the guidelines above

Proteinuria and hypertension: use doses of ACE inhibitors (ACEI) or angiotensin receptor blockers (ARB) recommended for children with other kidney diseases or hypertension

Renal toxicity: monitor frequently by doing urinalysis, and assessing the $\mathrm{SCr}$ levels at least once a year. Be aware of the ARV drugs that cause renal toxicity, and adjust their doses in children with CKD

Infants and young children: are at risk of developing diarrhea, dehydration, or salt wasting disorders. The treatment with ACEI and ARB should be monitored more frequently

Goal in adolescents: keep HIV RNA levels below 200 copies/ml, to prevent the transmission of HIV to sexual partners. Use drugs that do not cause fetal damage, and monitor patients treated with ACEI/ARB

breastfeeding women, and many are moving to implement viral load testing as the preferred means of monitoring people who are taking ART. New point-of-care viral load testing technologies offer further potential to expand this approach. Further, safer and more efficacious antiretroviral drugs are becoming available and a newer class of drugs - integrase inhibitors - is becoming more affordable for low- and middle-income countries.

More than 25 antiretroviral (ARV) drugs in six mechanistic classes are Food and Drug Administration (FDA) approved for treatment of HIV infection. These six classes include the nucleoside/nucleotide reverse transcriptase inhibitors (NRTIs), non-nucleoside reverse transcriptase inhibitors (NNRTIs), protease inhibitors (PIs), a fusion inhibitor (FI), a CCR5 antagonist, and integrase strand transfer inhibitors (INSTIs). In addition, two drugs, ritonavir (RTV) and cobicistat (COBI), are used solely as pharmacokinetic (PK) enhancers (i.e., boosters) to improve the PK profiles of some ARV drugs [73]. The initial ARV regimen for a treatment-naive adult or adolescent patient generally consists of two NRTIs, plus a drug from one of three drug classes: an INSTI, an NNRTI, or a PK-enhanced PI. A discussion related to the selection of the appropriate antiretroviral (ARV) drug treatments and the potential effect of these drugs on the kidney is beyond the scope of the present review. Table 2 describes important issues to take into consideration for the treatment of children and adolescents with HIVAN. Briefly, the kidney excretes all NRTIs except for abacavir, and their dosage should be adjusted according to the estimated glomerular filtration rate (eGFR). Other classes of ARV drugs (NNRTI, PI, fusion inhibitor, integrase, chemokine receptor antagonists) do not undergo significant kidney excretion and do not require adjustments in patients with kidney insufficiency. In all cases, nephrologists treating children living with HIV should work in close collaboration with infectious disease doctors familiar with these medications. Infants with perinatal HIV-1 infection should be treated with ART as soon as the diagnosis is established. Children with microalbuminuria or proteinuria should be followed more closely to prevent the progression of kidney diseases. In addition, ACE inhibitors (ACEi) appear to provide therapeutic benefits in adults and are recommended to treat proteinuria in children with HIV kidney diseases [73] (Table 2). For more detailed information regarding the specific treatment doses and ART regimens for children and adolescents with HIVAN, we recommend following the guidelines for the management of CKD in patients with HIV [73], as well as the guidelines for the use of antiretroviral agents in children and adolescents living with HIV [74].

Kidney transplantation and HIVAN Kidney transplantation of children with HIV-CKD has become an accepted treatment modality in recent years; however, significant outcome data in children are still lacking. Very promising results reported in pilot safety studies were performed in highly selected groups of HIV+ kidney transplant recipients [75]. These highly selected HIV+ kidney recipients showed excellent adherence to ART therapy, lack of severe immunosuppression $(\mathrm{CD} 4>200 \mathrm{cells} / \mu \mathrm{l})$, undetectable viremia $(<50$ HIV-1 RNA copies/ml) for 3 months prior to the kidney transplant, absence of AIDS-defining illness, successful immune reconstitution after ART, no 
history of opportunistic infections or neoplasms, and no active viral infections for at least 6 months previous to the kidney transplant. More studies done in the USA and Europe confirmed that kidney transplantation is a safe and effective treatment for kidney failure in HIV+ patients $[75,76]$, with equivalent patient and allograft survival to uninfected patients [75]. Unique challenges for HIV+ patients, however, include the high rates of acute rejection, delayed graft function, and significant drug-drug interactions [75]. In a prospective study including 150 kidney transplant recipients with undetectable plasma HIV-1 RNA, there was no histological evidence of recurrent de novo FSGS on light microscopy, nor was there any evidence of nephrotic range proteinuria [76]. Moreover, recurrent HIV nephropathy was not a factor in early graft loss (within 3 years of transplant in the USA trial). Unfortunately, very few pediatric nephrology transplant programs worldwide have transplanted a significant number of HIV+ children, and it is advisable to follow the adult guidelines. Finally, the limited availability of kidney transplants for children raises ethical concerns. To address this issue, surgeons in South Africa are pursuing kidney transplants using HIV+ kidney donors with good results [77]. Based on these data, in October 2016, surgeons at Johns Hopkins performed the first liver and kidney transplant in the USA between an HIV+ donor and HIV+ positive recipient and an ongoing clinical trial is assessing the outcome of more patients.

Perspectives During the last 36 years, great progress has been made in our understanding of the pathogenesis and treatment of children and adolescents with HIVAN. The quality of life and survival of children and adolescents living with HIV has improved in a remarkable manner and the prevalence of HIV-associated kidney diseases has decreased significantly. Nonetheless, many children living with HIV are reaching adulthood with proteinuria, mild low GFR levels, and at high risk of developing kidney failure later in life. Furthermore, we continue to see children with HIVAN and other HIV-associated kidney diseases in the Washington DC area. A number of challenges remain for the appropriate treatment of children living with HIV during the post-cART era, including the long-term persistence of viral reservoirs and inflammation resulting in end organ and kidney damage. From the renal pathological point of view, more work needs to be done to understand the mechanisms through which HIV-1 infects and injures kidney epithelial cells, define the cell types and mechanism modulating the regeneration and recovery of kidney epithelial cells, determine whether kidney epithelial and/or infiltrating mononuclear cells could become a reservoir for the virus, define the role of the APOL-1 risk variants in the pathogenesis of childhood HIVAN, and explore other potential risk factors associated with African ancestry. From the clinical and epidemiological point of view, more work needs to be done to develop a vaccine, prevent the vertical transmission of HIV-1, provide appropriate ART regiments to all children, maintain their viral suppression throughout childhood and adolescence, develop programs to identify children and adolescents undergoing the early stages of proteinuria, and define the safety and renal toxicity of new ART, as well as the outcomes of kidney transplants in children. These are all big healthcare challenges that will require the coordinated effort of people working in multiple disciplines. Hopefully, better prophylactic treatments and vaccines will be developed in the near future to achieve the ultimate goal of eradicating this disease.

\section{Compliance with ethical standards}

Conflict of interest The authors declare that they have no conflict of interest.

Open Access This article is licensed under a Creative Commons Attribution 4.0 International License, which permits use, sharing, adaptation, distribution and reproduction in any medium or format, as long as you give appropriate credit to the original author(s) and the source, provide a link to the Creative Commons licence, and indicate if changes were made. The images or other third party material in this article are included in the article's Creative Commons licence, unless indicated otherwise in a credit line to the material. If material is not included in the article's Creative Commons licence and your intended use is not permitted by statutory regulation or exceeds the permitted use, you will need to obtain permission directly from the copyright holder. To view a copy of this licence, visit http://creativecommons.org/licenses/by/4.0/.

\section{References}

1. Rao TK, Filippone EJ, Nicastri AD, Landesman SH, Frank E, Chen CK, Friedman EA (1984) Associated focal and segmental glomerulosclerosis in the acquired immunodeficiency syndrome. N Engl J Med 310:669-673

2. Strauss J, Abitbol C, Zilleruelo G, Scott G, Paredes A, Malaga S, Montane B, Mitchell C, Parks W, Pardo V (1989) Renal disease in children with the acquired immunodeficiency syndrome. N Engl J Med 321:625-630

3. Ray PE, Rakusan T, Loechelt BJ, Selby DM, Liu XH, Chandra RS (1998) Human immunodeficiency virus (HIV)-associated nephropathy in children from the Washington, D.C. area: 12 years' experience. Semin Nephrol 18:396-405

4. McCulloch MI, Ray PE (2008) Kidney disease in HIV-positive children. Semin Nephrol 28:585-594

5. Children, HIV and AIDS. Global Snapshot 2019. https://data. unicef.org/resources/children-hiv-aids-global-snapshot/data.unicef. org

6. Guidelines for the Use of Antiretroviral Agents in Pediatric HIVinfection https://aidsinfo.nih.gov/guidelines.pdf (accessed January 10, 2020)

7. Antiretroviral Therapy Cohort Collaboration (2017) Survival of HIV-positive patients starting antiretroviral therapy between 1996 
and 2013: a collaborative analysis of cohort studies. Lancet HIV 4: e349-e356

8. Chaparro AI, Mitchell CD, Abitbol CL, Wilkinson JD, Baldarrago G, Lopez E, Zilleruelo G (2008) Proteinuria in children infected with the human immunodeficiency virus. J Pediatr 152:844-849

9. Dickie P, Felser J, Eckhaus M, Bryant J, Silver J, Marinos N, Notkins AL (1991) HIV-associated nephropathy in transgenic mice expressing HIV-1 genes. Virology 185:109-119

10. Kopp JB, Klotman ME, Adler SH, Bruggeman LA, Dickie P, Marinos NJ, Eckhaus M, Bryant JL, Notkins AL, Klotman PE (1992) Progressive glomerulosclerosis and enhanced renal accumulation of basement membrane components in mice transgenic for human immunodeficiency virus type 1 genes. Proc Natl Acad Sci U S A 89:1577-1581

11. Ray PE, Liu XH, Robinson LR, Reid W, Xu L, Owens JW, Jones OD, Denaro F, Davis HG, Bryant JL (2003) A novel HIV-1 transgenic rat model of childhood HIV-1-associated nephropathy. Kidney Int 63:2242-2253

12. Rosenstiel P, Gharavi A, D'Agati V, Klotman P (2009) Transgenic and infectious animal models of HIV-associated nephropathy. J Am Soc Nephrol 20:2296-2304

13. Gharavi AG, Ahmad T, Wong RD, Hooshyar R, Vaughn J, Oller S, Frankel RZ, Bruggeman LA, D'Agati VD, Klotman PE, Lifton RP (2004) Mapping a locus for susceptibility to HIV-1-associated nephropathy to mouse chromosome 3. Proc Natl Acad Sci U S A 101: 2488-2493

14. Stevenson M (2003) HIV-1 pathogenesis. Nat Med 9:853-860

15. Ray PE, Liu XH, Henry D, Dye L 3rd, Xu L, Orenstein JM, Schuztbank TE (1998) Infection of human primary renal epithelial cells with HIV-1 from children with HIV-associated nephropathy. Kidney Int 53:1217-1229

16. Bruggeman LA, Ross MD, Tanji N, Cara A, Dikman S, Gordon RE, Burns GC, D'Agati VD, Winston JA, Klotman ME, Klotman PE (2000) Renal epithelium is a previously unrecognized site of HIV-1 infection. J Am Soc Nephrol 11:2079-2087

17. Hatsukari I, Singh P, Hitosugi N, Messmer D, Valderrama E, Teichberg S, Chaung W, Gross E, Schmidtmayerova H, Singhal PC (2007) DEC-205-mediated internalization of HIV-1 results in the establishment of silent infection in renal tubular cells. J Am Soc Nephrol 18:780-787

18. Khatua AK, Taylor HE, Hildreth JE, Popik W (2010) Nonproductive HIV-1 infection of human glomerular and urinary podocytes. Virology 408:119-127

19. Chen P, Chen BK, Mosoian A, Hays T, Ross MJ, Klotman PE, Klotman ME (2011) Virological synapses allow HIV-1 uptake and gene expression in renal tubular epithelial cells. J Am Soc Nephrol 22:496-507

20. Miyauchi K, Kim Y, Latinovic O, Morozov V, Melikyan GB (2009) HIV enters cells via endocytosis and dynamin-dependent fusion with endosomes. Cell 137:433-444

21. Connell BJ, Lortat-Jacob H (2013) Human immunodeficiency virus and heparan sulfate: from attachment to entry inhibition. Front Immunol 4:385

22. Li J, Das JR, Tang P, Han Z, Jaiswal JK, Ray PE (2017) Transmembrane TNF-alpha facilitates HIV-1 infection of Podocytes cultured from children with HIV-associated nephropathy. J Am Soc Nephrol 28:862-875

23. Marechal V, Clavel F, Heard JM, Schwartz O (1998) Cytosolic gag p24 as an index of productive entry of human immunodeficiency virus type 1. J Virol 72:2208-2212

24. Grell M, Douni E, Wajant H, Lohden M, Clauss M, Maxeiner B, Georgopoulos S, Lesslauer W, Kollias G, Pfizenmaier K, Scheurich $P$ (1995) The transmembrane form of tumor necrosis factor is the prime activating ligand of the $80 \mathrm{kDa}$ tumor necrosis factor receptor. Cell 83:793-802
25. Al-Lamki RS, Wang J, Vandenabeele P, Bradley JA, Thiru S, Luo D, Min W, Pober JS, Bradley JR (2005) TNFR1- and TNFR2mediated signaling pathways in human kidney are cell typespecific and differentially contribute to renal injury. FASEB J 19: $1637-1645$

26. De SK, Devadas K, Notkins AL (2002) Elevated levels of tumor necrosis factor alpha (TNF-alpha) in human immunodeficiency virus type 1-transgenic mice: prevention of death by antibody to TNF-alpha. J Virol 76:11710-11714

27. Bruggeman LA, Drawz PE, Kahoud N, Lin K, Barisoni L, Nelson PJ (2011) TNFR2 interposes the proliferative and NF-kappaBmediated inflammatory response by podocytes to TNF-alpha. Lab Investig 91:413-425

28. Ellaurie M, Rubinstein A (1992) Tumor necrosis factor-alpha in pediatric HIV-1 infection. AIDS 6:1265-1268

29. Hauber J, Malim MH, Cullen BR (1989) Mutational analysis of the conserved basic domain of human immunodeficiency virus tat protein. J Virol 63:1181-1187

30. Boykins RA, Mahieux R, Shankavaram UT, Gho YS, Lee SF, Hewlett IK, Wahl LM, Kleinman HK, Brady JN, Yamada KM, Dhawan S (1999) Cutting edge: a short polypeptide domain of HIV-1-tat protein mediates pathogenesis. J Immunol 163:15-20

31. Berkhout B, Silverman RH, Jeang KT (1989) Tat trans-activates the human immunodeficiency virus through a nascent RNA target. Cell 59:273-282

32. Garber ME, Wei P, KewalRamani VN, Mayall TP, Herrmann CH, Rice AP, Littman DR, Jones KA (1998) The interaction between HIV-1 tat and human cyclin T1 requires zinc and a critical cysteine residue that is not conserved in the murine CycT1 protein. Genes Dev 12:3512-3527

33. Ray PE, Bruggeman LA, Weeks BS, Kopp JB, Bryant JL, Owens JW, Notkins AL, Klotman PE (1994) bFGF and its low affinity receptors in the pathogenesis of HIV-associated nephropathy in transgenic mice. Kidney Int 46:759-772

34. Albini A, Benelli R, Presta M, Rusnati M, Ziche M, Rubartelli A, Paglialunga G, Bussolino F, Noonan D (1996) HIV-tat protein is a heparin-binding angiogenic growth factor. Oncogene 12:289-297

35. Chen P, Mayne M, Power C, Nath A (1997) The tat protein of HIV1 induces tumor necrosis factor-alpha production. Implications for HIV-1-associated neurological diseases. J Biol Chem 272:2238522388

36. Xie X, Colberg-Poley AM, Das JR, Li J, Zhang A, Tang P, Jerebtsova M, Gutkind JS, Ray PE (2014) The basic domain of HIV-tat transactivating protein is essential for its targeting to lipid rafts and regulating fibroblast growth factor- 2 signaling in podocytes isolated from children with HIV-1-associated nephropathy. J Am Soc Nephrol 25:1800-1813

37. Pike LJ (2009) The challenge of lipid rafts. J Lipid Res 50(Suppl): S323-S328

38. Chini B, Parenti M (2004) G-protein coupled receptors in lipid rafts and caveolae: how, when and why do they go there? J Mol Endocrinol 32:325-338

39. Zhong Y, Hennig B, Toborek M (2010) Intact lipid rafts regulate HIV-1 tat protein-induced activation of the rho signaling and upregulation of P-glycoprotein in brain endothelial cells. J Cereb Blood Flow Metab 30:522-533

40. Etienne-Manneville S, Hall A (2002) Rho GTPases in cell biology. Nature 420:629-635

41. Zhu L, Jiang R, Aoudjit L, Jones N, Takano T (2011) Activation of RhoA in podocytes induces focal segmental glomerulosclerosis. $\mathrm{J}$ Am Soc Nephrol 22:1621-1630

42. Soler-Garcia AA, Rakhmanina NY, Mattison PC, Ray PE (2009) A urinary biomarker profile for children with HIV-associated renal diseases. Kidney Int 76:207-214 
43. Page-McCaw A, Ewald AJ, Werb Z (2007) Matrix metalloproteinases and the regulation of tissue remodelling. Nat Rev Mol Cell Biol 8:221-233

44. Ensoli B, Gendelman R, Markham P, Fiorelli V, Colombini S, Raffeld M, Cafaro A, Chang HK, Brady JN, Gallo RC (1994) Synergy between basic fibroblast growth factor and HIV-1 tat protein in induction of Kaposi's sarcoma. Nature 371:674-680

45. He JC, Husain M, Sunamoto M, D'Agati VD, Klotman ME, Iyengar R, Klotman PE (2004) Nef stimulates proliferation of glomerular podocytes through activation of Src-dependent Stat3 and MAPK1,2 pathways. J Clin Invest 114:643-651

46. Ray PE, Tassi E, Liu XH, Wellstein A (2006) Role of fibroblast growth factor-binding protein in the pathogenesis of HIVassociated hemolytic uremic syndrome. Am J Physiol Regul Integr Comp Physiol 290:R105-R113

47. Korgaonkar SN, Feng X, Ross MD, Lu TC, D'Agati V, Iyengar R, Klotman PE, He JC (2008) HIV-1 upregulates VEGF in podocytes. J Am Soc Nephrol 19:877-883

48. Sasaki T, Hatta H, Osawa G (1999) Cytokines and podocyte injury: the mechanism of fibroblast growth factor 2-induced podocyte injury. Nephrol Dial Transplant 14(Suppl 1):33-34

49. Kriz W, Hahnel B, Rosener S, Elger M (1995) Long-term treatment of rats with FGF-2 results in focal segmental glomerulosclerosis. Kidney Int 48:1435-1450

50. Dijkman HB, Weening JJ, Smeets B, Verrijp KC, van Kuppevelt TH, Assmann KK, Steenbergen EJ, Wetzels JF (2006) Proliferating cells in HIV and pamidronate-associated collapsing focal segmental glomerulosclerosis are parietal epithelial cells. Kidney Int 70:338344

51. Ronconi E, Sagrinati C, Angelotti ML, Lazzeri E, Mazzinghi B, Ballerini L, Parente E, Becherucci F, Gacci M, Carini M, Maggi E, Serio M, Vannelli GB, Lasagni L, Romagnani S, Romagnani P (2009) Regeneration of glomerular podocytes by human renal progenitors. J Am Soc Nephrol 20:322-332

52. Barasch J, Qiao J, McWilliams G, Chen D, Oliver JA, Herzlinger D (1997) Ureteric bud cells secrete multiple factors, including bFGF, which rescue renal progenitors from apoptosis. Am J Phys 273: F757-F767

53. Das JR, Gutkind JS, Ray PE (2016) Circulating fibroblast growth factor-2, HIV-Tat, and vascular endothelial cell growth factor-A in HIV-infected children with renal disease activate rho-A and Src in cultured renal endothelial cells. PLoS One 11:e0153837

54. Ray PE, Liu XH, Xu L, Rakusan T (1999) Basic fibroblast growth factor in HIV-associated hemolytic uremic syndrome. Pediatr Nephrol 13:586-593

55. Genovese G, Friedman DJ, Ross MD, Lecordier L, Uzureau P, Freedman BI, Bowden DW, Langefeld CD, Oleksyk TK, Uscinski Knob AL, Bernhardy AJ, Hicks PJ, Nelson GW, Vanhollebeke B, Winkler CA, Kopp JB, Pays E, Pollak MR (2010) Association of trypanolytic ApoL1 variants with kidney disease in African Americans. Science 329:841-845

56. Tzur S, Rosset S, Shemer R, Yudkovsky G, Selig S, Tarekegn A, Bekele E, Bradman N, Wasser WG, Behar DM, Skorecki K (2010) Missense mutations in the APOL1 gene are highly associated with end stage kidney disease risk previously attributed to the MYH9 gene. Hum Genet 128:345-350

57. Kopp JB, Heymann J, Winkler CA (2017) APOL1 renal risk variants: fertile soil for HIV-associated nephropathy. Semin Nephrol 37:514-519

58. Ng DK, Robertson CC, Woroniecki RP, Limou S, Gillies CE, Reidy KJ, Winkler CA, Hingorani S, Gibson KL, Hjorten R, Sethna CB, Kopp JB, Moxey-Mims M, Furth SL, Warady BA, Kretzler M, Sedor JR, Kaskel FJ, Sampson MG (2017) APOL1associated glomerular disease among African-American children: a collaboration of the Chronic Kidney Disease in Children (CKiD) and Nephrotic Syndrome Study Network (NEPTUNE) cohorts. Nephrol Dial Transplant 32:983-990

59. Purswani MU, Patel K, Winkler CA, Spector SA, Hazra R, Seage GR 3rd, Mofenson L, Karalius B, Scott GB, Van Dyke RB, Kopp JB, Pediatric HIVAIDS Cohort Study (2016) Brief report: APOL1 renal risk variants are associated with chronic kidney disease in children and youth with perinatal HIV infection. J Acquir Immune Defic Syndr 73:63-68

60. Woroniecki RP, Ng DK, Limou S, Winkler CA, Reidy KJ, Mitsnefes M, Sampson MG, Wong CS, Warady BA, Furth SL, Kopp JB, Kaskel FJ (2016) Renal and cardiovascular morbidities associated with APOL1 status among African-American and nonAfrican-American children with focal segmental glomerulosclerosis. Front Pediatr 4:122

61. Ekulu PM, Nkoy AB, Betukumesu DK, Aloni MN, Makulo JRR, Sumaili EK, Mafuta EM, Elmonem MA, Arcolino FO, Kitetele FN, Lepira FB, van den Heuvel LP, Levtchenko EN (2019) APOL1 risk genotypes are associated with early kidney damage in children in sub-Saharan Africa. Kidney Int Rep 4:930-938

62. Nichols B, Jog P, Lee JH, Blackler D, Wilmot M, D'Agati V, Markowitz G, Kopp JB, Alper SL, Pollak MR, Friedman DJ (2015) Innate immunity pathways regulate the nephropathy gene Apolipoprotein L1. Kidney Int 87:332-342

63. Olabisi OA, Zhang JY, VerPlank L, Zahler N, DiBartolo S 3rd, Heneghan JF, Schlondorff JS, Suh JH, Yan P, Alper SL, Friedman DJ, Pollak MR (2016) APOL1 kidney disease risk variants cause cytotoxicity by depleting cellular potassium and inducing stress-activated protein kinases. Proc Natl Acad Sci U S A 113: 830-837

64. Lan X, Jhaveri A, Cheng K, Wen H, Saleem MA, Mathieson PW, Mikulak J, Aviram S, Malhotra A, Skorecki K, Singhal PC (2014) APOL1 risk variants enhance podocyte necrosis through compromising lysosomal membrane permeability. Am J Physiol Renal Physiol 307:F326-F336

65. Madhavan SM, O'Toole JF, Konieczkowski M, Ganesan S, Bruggeman LA, Sedor JR (2011) APOL1 localization in normal kidney and nondiabetic kidney disease. J Am Soc Nephrol 22: 2119-2128

66. Bruggeman LA, Wu Z, Luo L, Madhavan SM, Konieczkowski M, Drawz PE, Thomas DB, Barisoni L, Sedor JR, O'Toole JF (2016) APOL1-G0 or APOL1-G2 transgenic models develop preeclampsia but not kidney disease. J Am Soc Nephrol 27:3600-3610

67. Beckerman P, Bi-Karchin J, Park AS, Qiu C, Dummer PD, Soomro I, Boustany-Kari CM, Pullen SS, Miner JH, Hu CA, Rohacs T, Inoue $\mathrm{K}$, Ishibe $\mathrm{S}$, Saleem MA, Palmer MB, Cuervo AM, Kopp JB, Susztak K (2017) Transgenic expression of human APOL1 risk variants in podocytes induces kidney disease in mice. Nat Med 23: $429-438$

68. Fu Y, Zhu JY, Richman A, Zhang Y, Xie X, Das JR, Li J, Ray PE, Han Z (2017) APOL1-G1 in nephrocytes induces hypertrophy and accelerates cell death. J Am Soc Nephrol 28:1106-1116

69. Kruzel-Davila E, Shemer R, Ofir A, Bavli-Kertselli I, DarlyukSaadon I, Oren-Giladi P, Wasser WG, Magen D, Zaknoun E, Schuldiner M, Salzberg A, Kornitzer D, Marelja Z, Simons M, Skorecki K (2017) APOL1-mediated cell injury involves disruption of conserved trafficking processes. J Am Soc Nephrol 28:11171130

70. Zhaorigetu S, Wan G, Kaini R, Jiang Z, Hu CA (2008) ApoL1, a $\mathrm{BH} 3-$ only lipid-binding protein, induces autophagic cell death. Autophagy 4:1079-1082

71. Brady MT, Oleske JM, Williams PL, Elgie C, Mofenson LM, Dankner WM, Van Dyke RB, Pediatric AIDS Clinical Trials Group219/219C Team (2010) Declines in mortality rates and changes in causes of death in HIV-1-infected children during the HAART era. J Acquir Immune Defic Syndr 53:86-94 
72. Vermund SH, Blevins M, Moon TD, Jose E, Moiane L, Tique JA, Sidat M, Ciampa PJ, Shepherd BE, Vaz LM (2014) Poor clinical outcomes for HIV infected children on antiretroviral therapy in rural Mozambique: need for program quality improvement and community engagement. PLoS One 9:e110116

73. Lucas GM, Ross MJ, Stock PG, Shlipak MG, Wyatt CM, Gupta SK, Atta MG, Wools-Kaloustian KK, Pham PA, Bruggeman LA, Lennox JL, Ray PE, Kalayjian RC, HIV Medicine Association of the Infectious Diseases Society of America (2014) Clinical practice guideline for the management of chronic kidney disease in patients infected with HIV: 2014 update by the HIV Medicine Association of the Infectious Diseases Society of America. Clin Infect Dis 59: e96-e138

74. Panel on antiretroviral therapy and medical management of children living with HIV. Guidelines for the use of antiretroviral agents in pediatric HIV Infection. http://aidsinfo.nih.gov/con- tentfiles/ lvguidelines/pediatricguidelines.pdf (accessed April 14, 2020)
75. Stock PG, Barin B, Murphy B, Hanto D, Diego JM, Light J, Davis C, Blumberg E, Simon D, Subramanian A, Millis JM, Lyon GM, Brayman K, Slakey D, Shapiro R, Melancon J, Jacobson JM, Stosor V, Olson JL, Stablein DM, Roland ME (2010) Outcomes of kidney transplantation in HIV-infected recipients. N Engl J Med 363: 2004-2014

76. Touzot M, Pillebout E, Matignon M, Tricot L, Viard JP, Rondeau E, Legendre C, Glotz D, Delahousse M, Lang P, Peraldi MN (2010) Renal transplantation in HIV-infected patients: the Paris experience. Am J Transplant 10:2263-2269

77. Muller E, Kahn D, Mendelson M (2010) Renal transplantation between HIV-positive donors and recipients. N Engl J Med 362: 2336-2337

Publisher's note Springer Nature remains neutral with regard to jurisdictional claims in published maps and institutional affiliations. 